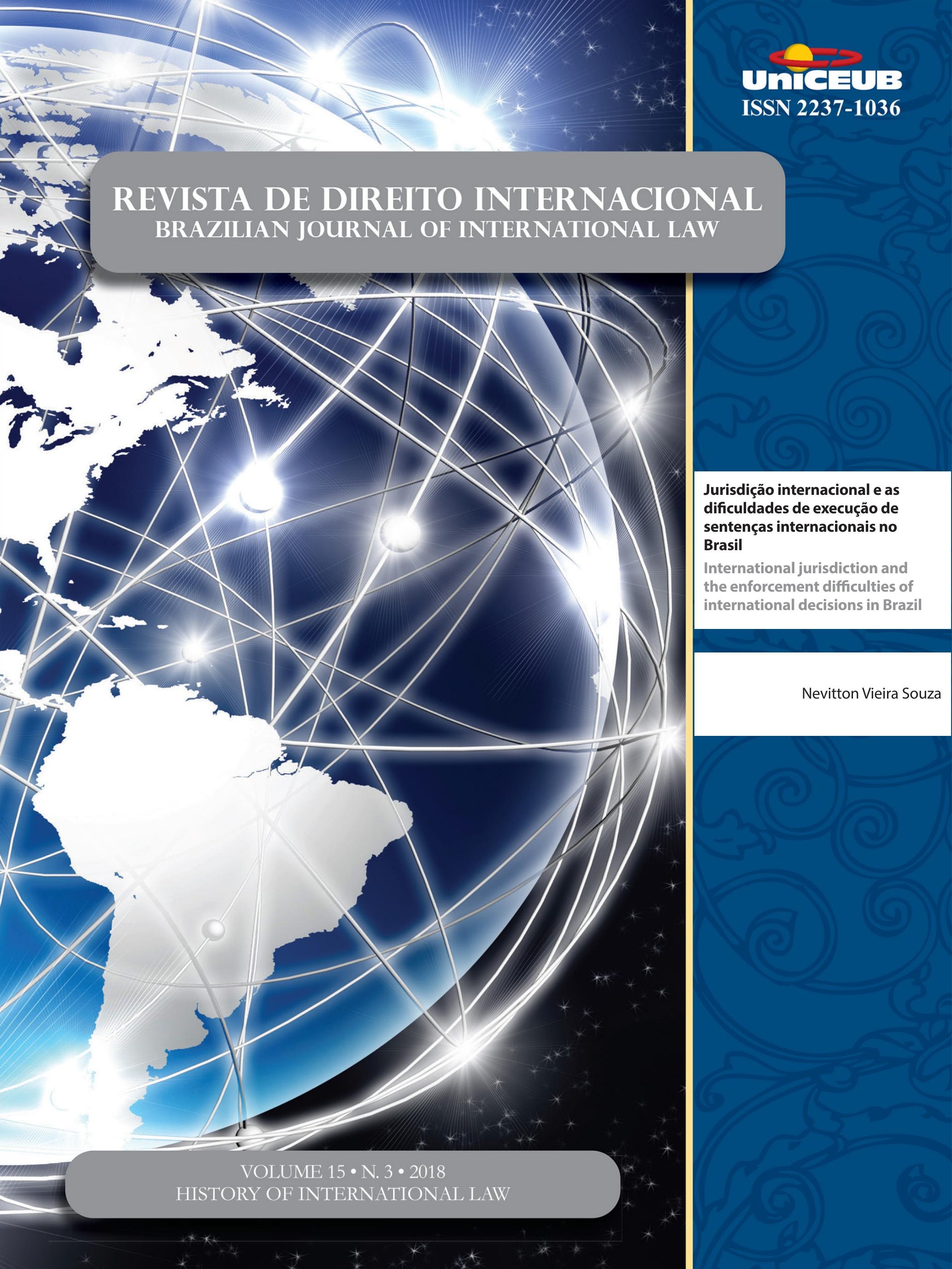




\section{Sumário}

I. Dossiê Especial: History of International Law ...................................1

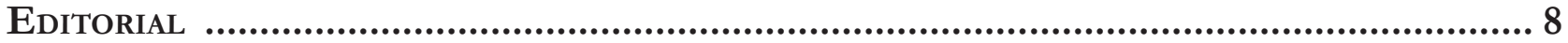

What does it mean to apply history in international law studies? ....................................................... 8

Arthur Roberto Capella Giannattasio

SuR LA NATURE DU Droit ISLAMIQUe............................................................................14

Hocine Benkheira

Islamic Shari’a Law, History and Modernity: Some Reflections .................................25 Suleiman A. Mourad

The (Un)practical Secularization Process: International Law and Religion as So-

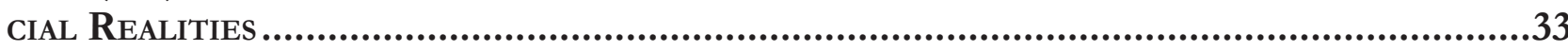

Douglas de Castro

BRAZILIAN LITERATURE ON INTERNATIONAL LAW DURING THE EMPIRE REGIME. OR THE DIFFUSION OF INTERNATIONAL LAW IN THE PERIPHERIES THROUGH APPROPRIATION AND ADAPTATION.

Airton Ribeiro da Silva Júnior

Natural, POSitivo, romano E Universal? INVESTigaÇão SObre O Direito das GENTES EM

Tomás de Aquino

Rafael Zelesco Barretto

II. Artigos sobre outros temas

VINCULAÇÃO DOS DIREITOS ECONÔMICOS, SOCIAIS E CULTURAIS: UMA DISCUSSÃO DO DESENVOLVImento humano com base no conceito de Amartya Sen sobre o mínimo existencial.....99

Natalia Mascarenhas Simões Bentes e Yasmim Salgado Santa Brígida

A NOVA LeI de MigraÇão E A PROTEÇão CONFERIDA AO APÁtrida: ALINHAMENTO BRASILEIRO AO PADRÃO INTERNACIONAL DE DIREITOS HUMANOS

Pedro Henrique de Faria Barbosa e Sylvio Loreto

E se o Supremo Tribunal Federal (STF) restabelecer a vigência da Convenção n. 158 
da Organização Internacional do Trabalho (OIT) na ordem Jurídica brasileira? SoBRE UMA POSSÍVEL REVIRAVOLTA, PELA VIA DO DIREITO INTERNACIONAL, DAS LEIS TRABALHISTAS BRASILEIRAS 138

Daniel Damasio Borges

JULGADOS DA CORTE INTERAMERICANA SOBRE CASOS BRASILEIROS E POLÍTICAS PÚBLICAS: REFLEXÕES ACERCA DE POSSÍVEIS INFLUIÇÕES 165

Rafael Osvaldo Machado Moura

CREATING BRIDGES BETWEEN INTERNATIONAL RELATIONS THEORY AND INTERNATIONAL HUMAN RIGHTS LAW: CONSTRUCTIVISM AND THE ROLE OF BRAZIL IN THE INTER-AMERICAN SYSTEM OF HUMAN RIGHTS 179

Ismael Francisco de Souza, Luciana Rocha Leme e Erick da Luz Scherf

Justiça de transição na Argentina e o Sistema Interamericano de Direitos Humanos: uMa ANÁlise do CASo Luis Muiña (“REgRa 2x1”) 199

Emilio Peluso Neder Meyer e Jessica Holl

A legalidade e legitimidade da INTERVEnÇão humanitÁria: UMA MEDIDA AINDA NECESSÁRIa.219 Natália Caye Batalha Boeira

O Acordo de Escazú E o ACESSo À INFORMaÇão AMbiental no Brasil. 252 Érica Bezerra Queiroz Ribeiro e Bruno Amaral Machado

Dos POVOS NATIVOS AO SURGIMENTO DOS MOVIMENTOS SOCIAIS: INFLUÊNCIAS DOS DISCURSOS JURÍDICOS, RELIGIOSOS E MÉDICOS PARA A CONSTRUÇÃO DO CONCEITO DE HOMOSSEXUALIDADE NO BRASIL .267 Bruno Rafael Silva Nogueira Barbosa e Robson Antão de Medeiros

Aspectos Jurídicos da PARTicipaÇão dA UNião Europeia NA OMC: COMPREENDENdo SUTILEZAS DE UM DELICADO ENLACE. 291

Camilla Capucio

Path to judicial activism? The use of "Relevant rules of international law" by the WTO Appellate Body

Mariana Clara de Andrade

LEVEZA E PESO NA MEDIAÇÃO COMERCIAL INTERNACIONAL: O CONTEÚDO JURÍDICO DO ACORDO CORPORATIVO MEDIADO E SUA INCORPORAÇÃo PELO DiREITO BRASILEIRO .324 Henrique Lenon Farias Guedes 
JURISDIÇÃO INTERNACIONAL E AS DIFICULDADES DE EXECUÇÃO DE SENTENÇAS INTERNACIONAIS NO BRASIL

Nevitton Vieira Souza

O DEVER DE COOPERAÇÃo NOS CONTRATOS DE VENDA INTERNACIONAL DE MERCADORIAS: PRESSUPOSTOS TEÓRICOS E REPERCUSSÕES PRÁTICAS DA CLÁUSULA GERAL DA BOA-FÉ OBJETIVA PARA A APLICAÇÃo DA CISG .358

Angelo Gamba Prata de Carvalho

A DiMENSÃo JURÍdiCA DO IMPERIALISMO NA (DES)ORDEM GLOBAL CAPITALISTA: UMA ANÁLISE COM BASE NA CRÍTICA MARXISTA AO DIREITO INTERNACIONAL E ÀS RELAÇÕES POLÍTICO-ECONÔMICAS DE DOMINAÇÃO E DEPENDÊNCIA.

Thomaz Delgado De David, Maria Beatriz Oliveira da Silva e Rosane Beatris Mariano da Rocha Barcellos Terra

A participaÇão de Brasil e Estados Unidos na formulação das regras multilaterais do

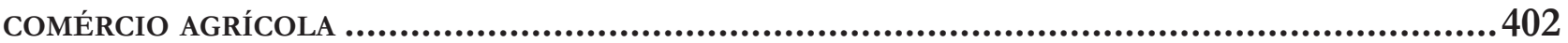

Vera Thorstensen, Vivian Daniele Rocha Gabriel e Alebe Linhares Mesquita

A galáxia lex e a construÇão de um Sistema jurídico transnacional ........................ 441

Eugênia Cristina Nilsen Ribeiro Barza e Jéssyka Maria Nunes Galvão

Has the Ability of Truth Commissions to Recommend Amnesty Been Effective in Enhancing Perpetrator Cooperation? 453 Jeremy Sarkin

A CONCEPTUAL PAPER ON THE POLICY-FRAMEWORK THAT MIRRORS THE DYNAMIC LINK BETWEEN Human Security, Social Protection and Safety Nets, and Food and Nutritional Security: The Case of the "Gulayan sa Paaralan Program", the Philippines.... 478 Renato Lagapa Base

INCENTIVISING SMALLHOLDER FARMER LIVELIHOODS AND CONSTRUCTING FOOD SECURITY THROUGH HOME-GROWN SCHOOL FEEDING: EVIDENCE FROM NORTHERN GHANA .491

Clement Mensah

Policy COHERENCE In THE IMPLEMENTATION OF THE 2030 AgENDA FOR SUSTAINABLE DEVELOpment: the Brazilian School Feeding Programme Case Study .506 Mariana Werlang Girardi 


\title{
Jurisdição internacional e as dificuldades de execução de sentenças internacionais no Brasil* $^{*}$
}

\author{
International jurisdiction and the \\ enforcement difficulties of international \\ decisions in Brazil
}

Nevitton Vieira Souza **

\section{Resumo}

O presente artigo tem por objeto de análise as dificuldades observadas na execução de sentenças internacionais no Brasil, com base na perspectiva do fenômeno da jurisdicionalização da sociedade internacional moderna. Ao ser verificado que o Brasil, atualmente, está vinculado à jurisdição internacional de seis tribunais e órgãos internacionais, o exame sobre os mecanismos domésticos de implementação das sentenças internacionais se evidencia, notadamente, em razão do seu descumprimento resultar em nova responsabilização internacional do Estado. Este trabalho objetiva aferir os mecanismos domésticos de execução de sentenças internacionais, com corte metodológico nas sentenças internacionais já existentes em face do Brasil, notadamente as oito provenientes da Corte Interamericana de Direitos Humanos. Constatou-se que à inexistência de normas especificas nessa matéria no ordenamento interno é somada a limitação excessiva dos projetos de leis-ponte, propostos perante o Congresso Nacional e analisados neste trabalho. Foi empregado o método dedutivo-comparativo, com base em fontes bibliográficas e documentais indiretas.

Palavras-chave: Sentença internacional. Cumprimento de sentença internacional. Lei-ponte. Cooperação jurídica internacional.

* Recebido em: 14/09/2018 Aprovado em: 15/11/2018

** Doutorando em Direito Internacional e Comparado pela Faculdade de Direito da Universidade de São Paulo, USP (2018). Mestre em Direito Processual pela Universidade Federal do Espírito Santo, UFES (2015). Professor do Departamento de Direito da UFES (2015-2017). Advogado e consultor jurídico. E-mail: nevitton@usp.br.

\section{Abstract}

This article analyzes the difficulties observed in the enforcement of international decisions in Brazil, from the perspective of the phenomenon of the jurisdictionalisation of modern international society. Considering that Brazil is currently bound by the international jurisdiction of six international tribunals, the examination of the domestic mechanisms for the implementation of international judgments is evidenced, especially because the failure to comply with a decision results in new international responsibility of the State. This research aims at examining the domestic mechanisms for the execution of international decisions, with emphasis on the existing international judgments in relation to Brazil, especially the eight decisions of the Inter-American Court of Human Rights. It was verified that to the 
lack of specific norms in this matter in the internal order is added the excessive limitation of the projects of "bridge-law" (implementing rules), proposed in the $\mathrm{Na}$ tional Congress and analyzed in this essay. The deductive-comparative method was used, based on indirect bibliographic and documentary sources.

Keywords: International decision. Enforcement of international decision. Implementing rules. International legal cooperation.

\section{INTRODUÇão}

O cenário globalizado proporcionou o adensamento das relações na sociedade internacional contemporânea, incrementando sua dinâmica com agendas e desafios resultantes da pluralidade e fluidez da relação entre o global e o local. Nesse contexto, o Direito Internacional se apresenta como instrumento hábil e apropriado para regular e solucionar os problemas que emergem da inter-relação constante entre os atores dessa revolução globalizante ${ }^{1}$.

A observada institucionalização das relações interestatais, especialmente no período pós-Segunda Guerra Mundial, acompanhada pela criação da Organização das Nações Unidas (ONU), reforçou o primado do Direito Internacional. Reforço refletido no desenvolvimento dos mecanismos jurisdicionais de resolução de controvérsias, os quais visam promover a busca efetiva da paz em detrimento da utilização da força, em atenção à justiça internacional. A prevenção do uso da força mediante a resolução pacífica de conflitos constitui, historicamente, um dos principais objetivos do Direito Internacional ${ }^{2}$.

$\mathrm{O}$ acesso à justiça enquanto direito humano fundamental goza de reconhecido desenvolvimento normativo, jurisprudencial e doutrinário, notadamente no tocante a sua instrumentalização no direito interno, em face do Estado, tendo este como seu garantidor principal $^{3}$. No que tange ao acesso à justiça internacional,

1 MENEZES, Wagner. Ordem global e transnormatividade. Ijuí: Unijuí, 2005. p. 27.

2 SPAIN, Anna. Using international dispute resolution to address the compliance question in international law. Georgetown Journal of International Law, Washington, D.C., v. 40, n. 3, 2009. p. 818-820.

3 POLIDO, Fabrício B. P. Direito processual internacional e o contencioso internacional privado. Curitiba: Juruá, 2013. p. 42. CAPPELLETTT, Mauro; GARTH, Bryant. Acesso à justiça. Porto Alegre: Fabris, 1988. todavia, a temática permanece sem profundas explorações, muito embora o surgimento de novos sujeitos de Direito Internacional ao lado do Estado - Organizações Internacionais e indivíduos — tenha potencializado sua necessidade.

Pode-se afirmar, entretanto, conforme Wagner Menezes ${ }^{4}$, que a ideia de acesso à justiça internacional está permeada pela: a) existência de um conjunto de direitos assegurados no plano internacional; b) identificação dos titulares desses direitos oriundos de normas internacionais; c) presença de mecanismos jurídicos disponíveis e acessíveis, nos quais se possa invocar proteção contra lesão aos direitos assegurados; e d) exigência de efetividade às decisões judiciais emanadas dos tribunais internacionais.

Destarte, explicita-se a necessária materialidade do direito ao acesso à justiça no plano internacional ${ }^{5}$, uma vez que não basta a mera previsão em abstrato de direitos, sendo essencial a identificação de seus titulares e que estes possam ter acesso desimpedido a meios jurídicos aptos à concretização e à defesa, quando da ocorrência de lesão. Para tanto, imperioso que se dê cumprimento efetivo às decisões oriundas do tribunal internacional competente.

Oportunamente, cumpre destacar que, por sentenças internacionais, objeto central deste trabalho, entende-se os pronunciamentos terminativos obtidos em processos tramitados em órgãos internacionais que exercem a jurisdição internacional, conforme estabelecido em seus respectivos tratados constitutivos. As sentenças internacionais fazem parte de um conjunto maior de atos praticados pelos chamados Tribunais ou Cortes internacionais, dos quais também fazem parte decisões interlocutórias, medidas provisionais e outros atos que visem à obtenção de provas, cientificação e notificação dos sujeitos envolvidos nos atos processuais neles desenvolvidos.

As sentenças internacionais, vale salientar, não se confundem com as sentenças estrangeiras, posto que estas são provenientes de uma jurisdição nacional considerada estrangeira desde a perspectiva de uma determinada ordem jurídica nacional. As sentenças estrangeiras,

p. $9-13$.

4 MENEZES, Wagner. Tribunais Internacionais: jurisdição e competência. São Paulo: Saraiva, 2013. p. 37.

5 TRINDADE, Antonio Augusto Cançado. El derecho de acceso a la justicia em su amplia dimension. Santiago: Librotecnia, 2008. p. 61-62. 
para que possam produzir efeitos jurídicos em ordem jurídica distinta daquela na qual fora prolatada, via de regra, precisam se submeter a processo de reconhecimento regido por normas previamente estabelecidas no ordenamento doméstico ${ }^{6}$. Por outro lado, as sentenças internacionais se originam de órgãos aos quais o Estado já está previamente vinculado, comprometendo-se a obedecer e dar cumprimento aos atos deles emanados, sob pena de responsabilização internacional ${ }^{7}$.

Tendo como corte metodológico a execução de sentenças internacionais na ordem jurídica nacional brasileira, a presente pesquisa estabelece contato com os órgãos jurisdicionais internacionais dos quais o Brasil efetivamente faz parte atualmente, quais sejam a Corte Internacional de Justiça ${ }^{8}$, o Tribunal Internacional do Direito do Mar", o Órgão de Solução de Controvérsias da $\mathrm{OMC}^{10}$, o Tribunal Penal Internacional ${ }^{11}$, a Corte Interamericana de Direitos Humanos ${ }^{12}$ e o Tribunal Permanente de Revisão do Mercosul ${ }^{13}$.

Pontua-se, entretanto, que, dentre os seis órgãos jurisdicionais internacionais acima citados, o Brasil foi condenado, até o presente momento, pela Corte Interamericana de Direitos Humanos e pelo Órgão de Solução de Controvérsias da OMC. Tendo em vista as peculiaridades das decisões oriundas deste, as quais, via de regra, não ensejam uma execução propriamente dita no âmbito interno do Estado vitorioso da disputa, mas potencializa a realização de acordos entre os Estados nela envolvidos ${ }^{14}$, o presente trabalho delas não se ocupará em específico. Doutro turno, o Brasil já foi condenado oito vezes pela Corte Interamericana, em cujas sentenças encontram-se obrigações de distintas naturezas e que desafiam os mecanismos tradicionais domésticos

6 SOUZA, Nevitton V. Sistemas de reconbecimento de sentença estrangeira no Brasil: panorama e adequação normativos. 2015, 137 f. Dissertação (Mestrado) apresentada ao Programa de Pós-Graduação em Direito da Universidade Federal do Espírito Santo, Vitória, 2015. p. 77-81.

7 AZAR, Aïda. L'exécution des décisions de la Cour internationale de justice. Bruxelas: Bruylant: l'Université de Bruxelles, 2003.

8 Promulgado pelo Decreto n. 19.841, de 22 de outubro de 1945.

9 Promulgado pelo Decreto n. 99.165, de 12 de março de 1990.

10 Promulgado pelo Decreto n. 1.355, de 30 de dezembro de 1994.

11 Promulgado pelo Decreto n. 4.388, de 25 de setembro de 2002. 12 Promulgado pelo Decreto n. 4.463, de 08 de novembro de 2002.

13 Promulgado pelo Decreto n. 4.982, de 09 de fevereiro de 2004. 14 CAPUCIO, Camilla. A natureza jurídica das decisões do Sistema de Solução de Controvérsias da OMC: solucionando um imbróglio. Revista de Direito Internacional, Brasília, v. 14, n. 1, 2017, p. 316-340. no tocante à execução das sentenças internacionais, a fim de que o Estado não recaia em nova responsabilização internacional.

Por essa razão, o presente ensaio tem por objetivo específico tecer análise sobre as dificuldades procedimentais e institucionais enfrentadas pelas sentenças internacionais na ordem interna nacional brasileira. Nesse propósito, inicialmente será abordado o fenômeno da jurisdicionalização da sociedade internacional, para, na sequência, passar ao estudo da sentença internacional nesse contexto de múltiplas jurisdições internacionais. Em seguida, as dificuldades encontradas no percurso de cumprimento de sentenças internacionais no Brasil serão evidenciadas. Ao final, serão analisadasas experiências de projetos legislativos que visam estabelecer leis-ponte no âmbito nacional. Reitera-se que foi empregado, no presente trabalho, o método dedutivo-comparativo, a partir de fontes bibliográficas e documentais indiretas.

\section{JURISDICIONALIZAÇÃO DA SOCIEDADE INTERNACIONAL}

O fenômeno da jurisdicionalização da sociedade internacional, mediante o qual se observa a estruturação de tribunais internacionais, tem como escopo fundamental a realização efetiva da justiça, consagrando o império do direito no tocante à resolução pacífica das controversas internacionais ${ }^{15}$. Enquanto instrumentos para o alcance da paz mundial, com a superação do uso da força, os tribunais internacionais exercem a jurisdição que lhes é conferida pelos Estados, por meio de tratados internacionais específicos, e mediante os quais são competentes para dirimir disputas à luz das fontes normativas do direito internacional.

A jurisdicionalização internacional se desenvolveu assentada na ideia de segurança jurídica e aperfeiçoamento do Direito Internacional, num contexto de crescente positivação de normas internacionais. A institucionalização de tribunais internacionais permanentes, desde suas experiências anteriores à Segunda Guerra até a criação da Corte Internacional de Justiça, principal órgão judiciário da ONU, constitui prestígio ao primado

15 MENEZES, Wagner. Tribunais Internacionais: jurisdição e competência. São Paulo: Saraiva, 2013. p. 136-143. 
do Direito ${ }^{16}$ e mitigação de métodos violentos nas relações internacionais ${ }^{17}$.

A jurisdicionalização da sociedade internacional, densificada a partir da segunda metade do século XX com a multiplicação de jurisdições internacionais nos planos global e regional, com competência sobre matérias gerais e especializadas — tornou complexo o sistema internacional de solução pacífica de controvérsias, uma vez que cada tribunal guarda particularidades formais e inexistem normas organizacionais comuns que os compatibilize. De todo modo, o fenômeno evidencia a insuficiência das jurisdições internacionais preexistentes e a regionalização do Direito Internacional ${ }^{18}$, mas aponta, outrossim, para a especialização e o aprimoramento da tutela jurisdicional internacional.

Destarte, apesar da ausência de uniformidade conceitual, sobretudo pelas singularidades existentes, os tribunais internacionais se apresentam como órgãos permanentes e autônomos, dotados de poder jurisdicional conferido pelos Estados, a partir do qual possuem o poder-dever de decidir casos concretos mediante a aplicação do Direito Internacional, e cujas decisões tenham caráter vinculante sobre os jurisdicionados ${ }^{19}$.

O processo de jurisdicionalização da sociedade internacional observou o surgimento, em 1922, da Corte Permanente de Justiça Internacional, no âmbito da Liga das Nações. Com o fim da Segunda Grande Guerra, ao suceder a Liga das Nações, a Organização das Nações Unidas trouxe, em seu bojo, a Corte Internacional de Justiça enquanto principal órgão judicial de resolução de conflitos entre os Estados, em 1945.

Com o crescente processo de institucionalização da sociedade internacional, assim como pela multiplicação de tratados internacionais, a disciplinar distintas matérias especializadas, a jurisdicionalização da ordem internacional se adensou, mediante o surgimento de diferentes tribunais internacionais especializados, tanto

16 SHAW, Malcolm. International law. 6. ed. New York: Cambridge University Press, 2008. p. 30-31.

17 TOMUSCHAT, Christian. International law: ensuring the survival of mankind on the eve of a new century: general course on public international law. Recueil des Cours, Academie de Droit International de la Haye, v. 281, p. 9-438, 1999. p. 391-395.

18 KARAGIANNIS, Syméon. La multiplication des juridictions internationales: un système anarchique? In: LA JURIDICTIONNALISATION du droit international. Societe Française pour le Droit International, Paris: Pedone, 2003. p. 15-16.

19 MENEZES, Wagner. Tribunais Internacionais: jurisdição e competência. São Paulo: Saraiva, 2013. p. 151-152. no âmbito regional como no universal.

No plano regional, a Europa assistiu o surgimento do Tribunal de Justiça (1952) e da Corte Europeia de Direitos Humanos (1959), bem como na América se institucionalizaram a Corte Interamericana de Direitos Humanos (1979), o Tribunal de Justiça da Comunidade Andina (1979), a Corte Centro-Americana de Justiça (1994), o Tribunal Permanente de Revisão do Mercosul (2004) e a Corte de Justiça do Caribe (2005). Na África, observa-se o Tribunal Africano dos Direitos Humanos e dos Povos (2006).

No plano universal, também é possível observar o surgimento de outros órgãos jurisdicionais para a resolução de controvérsias, todavia com temáticas especializadas em comparação à Corte Internacional de Justiça. São os casos do Tribunal Internacional do Mar (1996) e do Tribunal Penal Internacional (2004). No seio da Organização Mundial do Comércio (OMC), tem-se, ainda, o Sistema de Solução de Controvérsias da OMC, em funcionamento desde 1995.

Ademais, também, no plano global, não se caracterizando como tribunais internacionais propriamente ditos, mas se configurando como grandes centros administradores de arbitragens internacionais - esta, sim, modalidade jurisdicional de resolução de controvérsias —, destacam-se a Corte Permanente de Arbitragem, estabelecida em 1899, e o Centro Internacional para a Solução de Disputas sobre Investimentos (1965), inserido no âmbito do Banco Mundial.

O quadro apresentado demonstra uma multiplicidade de foros internacionais competentes para o exercício da atividade jurisdicional em face de relações jurídicas internacionais de distintas naturezas - comercial, ambiental, protetiva dos direitos humanos etc. - , as quais envolvem distintos atores - Estados, indivíduos, investidores, multinacionais - numa sociedade internacional cada vez mais complexa.

Se, de um lado, como afirma Syméon Karagiannis ${ }^{20}$, a expansão quantitativa de órgãos jurisdicionais no âmbito internacional se deu em virtude de um processo de regionalização, especialização e de insuficiência das jurisdições internacionais globais existentes, também é

20 KARAGIANNIS, Syméon. La multiplication des juridictions internationales: un système anarchique? In: LA JURIDICTIONNALISATION du droit international. Societe Française pour le Droit International, Paris: Pedone, 2003. p. 15-16. 
possível afirmar que tal impulso somente foi possível mediante a consciência de que os mecanismos jurisdicionais domésticos e unilaterais são insuficientes para solucionar demandas comuns à sociedade internacional.

Ocorre que, para além da estruturação de jurisdições internacionalmente competentes para dirimir disputas internacionais, é essencial que os órgãos que exerçam a atividade jurisdicional sejam dotados de instrumentos hábeis para sua efetiva atuação. O que envolve a implementação de mecanismos de cooperação jurídica internacional ${ }^{21}$, horizontais e verticais, os quais possibilitem a realização de todos os atos essenciais ao exercício da jurisdição internacional e à prestação adequada e suficiente da tutela jurídica.

\section{Sentenças internacionais}

Duas características se destacam nas decisões dos tribunais internacionais. A primeira é sua posição no rol das fontes do Direito Internacional, constante no art. 38 do Estatuto da Corte Internacional de Justiça e consagrada pela doutrina internacionalista ${ }^{22}$. À função integradora das decisões dos tribunais internacionais, agindo na determinação das normas jurídicas a serem aplicadas no caso concreto, é adicionada pelo exercício da jurisdição internacional a aptidão para resolução de litígios mediante o estabelecimento de norma individual e concreta. Esta, que constitui obrigação normativa, se ignorada, leva o sujeito à prática de novo ilícito internacional, suscetível à responsabilização ${ }^{23}$.

A coercitividade das decisões dos tribunais internacionais, sua eficácia jurídica, é tema que desperta desacordo doutrinário, opondo aqueles que enxergam na sentença internacional um grau de vinculatividade inerente ao Princípio da Boa-fée ${ }^{4}$ - em decorrência dos compromissos assumidos quando da vinculação do Estado ao tratado constitutivo do tribunal internacional,

21 GEROMEL, Vitor. Tribunais internacionais e o Poder Judiciário brasileiro. 2014. 172 f. Dissertação (Mestrado) - Programa de Pós-Graduação em Direito Internacional da Universidade de São Paulo, São Paulo, 2014. p. 113-114.

22 REZEK, José Francisco. Direito internacional público: curso elementar. 15. ed. São Paulo: Saraiva, 2014. p. 178.

23 AZAR, Aïda. L'exécution des décisions de la Cour internationale de justice. Bruxelas: Bruylant: l'Université de Bruxelles, 2003.

24 MENEZES, Wagner. Tribunais Internacionais: jurisdição e competência. São Paulo: Saraiva, 2013. p. 37; 135. bem como a sua jurisdição internacional —, àqueles que focalizam a estrutura horizontal de poder existente na esfera internacional, atrelando a efetividade da sentença internacional a considerações políticas conjunturais ${ }^{25}$.

O estudo da efetividade da sentença internacional tem que relação com a investigação do alcance dos princípios e valores para os quais os tribunais internacionais foram criados, sua repercussão na sociedade internacional e sua contribuição para o rompimento de uma tradição bélica em direção à consagração do primado do Direito Internacional. O grau de desenvolvimento alcançado pelo Direito Internacional contemporâneo demanda estruturas institucionalizadas para o exercício da jurisdição internacional, a fim de garantir a prevalência da escola jurídica sobre a escola diplomática na resolução das controvérsias emergentes. Assim, o cumprimento das decisões emanadas pelos Tribunais Internacionais reflete a efetividade de seu funcionamento, constituindo objeto digno de aprofundamento científi$\mathrm{co}^{26}$.

Nesse diapasão, torna-se evidente a importância que deve ser reconhecida ao produto final da atividade jurisdicional internacional, isto é, à sentença internacional proveniente do exercício legítimo da jurisdição internacionalmente atribuída aos tribunais internacionais. A sentença internacional é, ressalte-se, decorrência lógica e jurídica do exercício da jurisdição internacional e, portanto, deve vincular os Estados que se submeteram à jurisdição do órgão competente para proferi-la. Assim, no momento em que o Estado resolve se submeter à jurisdição obrigatória de um tribunal internacional, está, também, resolvendo se submeter às decisões por ele emitidas. É o que decorre da expectativa de boa-fé gerada perante a sociedade internacional, bem como do dever de cumprir as obrigações internacionalmente assumidas, conforme a Convenção de Viena sobre o Direito dos Tratados (1969).

Espera-se, portanto, que, diante de uma sentença internacional, os Estados envolvidos no litígio, e que tenham contra si obrigações a cumprirem, cumpram, espontaneamente, o comando decisório. Ocorre que essa recente realidade de jurisdições internacionais coe-

25 WENDPAP, Friedmann; KOLOTELO, Rosane. Direito internacional. Rio de Janeiro: Elsevier, 2007. p. 213.

26 CHARNEY, Jonathan I. Is international law threatened by multiple international tribunals?. Recueil des Cours, Academie de Droit International de la Haye, v. 271, p. 101-382, 1998. p. 117. 
xistindo com jurisdições nacionais impõe aos Estados reflexões sobre suas tradicionais estruturas domésticas, de modo a pavimentar caminhos para que as estruturas institucionais internas possam dialogar e cooperar com a adequada atuação das instituições internacionais.

\section{Cumprimento de sentenças internacionais}

Conforme observa Bárbara Campos ${ }^{27}$, a implementação das sentenças internacionais no Brasil envolve três questões centrais. A primeira é relativa à natureza das sentenças internacionais, debate que, ao seu ver, já se encontra superado por hora, na medida em que a aplicação imediata de seus efeitos jurídicos no âmbito doméstico é observada, notadamente em razão do cumprimento espontâneo pelo Estado brasileiro de determinações, essencialmente pecuniárias, da Corte Interamericana de Direitos Humanos.

A segunda questão seria relativa à posição que as sentenças internacionais ocupariam no ordenamento jurídico brasileiro. Consoante apresenta, a questão está entrelaçada com o debate, já clássico, sobre a posição normativa dos tratados internacionais na ordem interna. Contudo, cumpre salientar que os debates clássicos sobre a interação da ordem nacional e internacional, tendo como plano de fundo as teorias monista e dualista, podem ser superados pela visão mais atual apresentada pela teoria da transnormatividade ${ }^{28}$.

A Teoria da Transnormatividade evidencia as interações entre as ordens domésticas e a internacional, demonstrando que estas se mostram tão fluídas no contexto social profundamente modificado pelo adensamento da globalização, que não se pode negar as influências das dinâmicas internacionais, como seus novos atores, sobre o âmbito normativo nacional. Ainda que formalmente o Estado se apresente refratário às normas internacionais, materialmente é possível identificar, desde o texto constitucional ao regulamentar, possíveis influências dos avanços normativos internacionais - seja em matéria de proteção aos direitos humanos, seja em matéria comercial, ambiental, contratual etc.

27 CAMPOS, Bárbara Pincowsca Cardoso. A trajetória da implementação de sentenças da Corte Interamericana de Direitos Humanos no Brasil. Revista do Instituto Brasileiro de Direitos Humanos, Fortaleza, v. 14, n. 14, 2014.

28 MENEZES, Wagner. Ordem global e transnormatividade. Ijuí: Unijuí, 2005.
Destarte, em relação ao ordenamento jurídico brasileiro - para além da posição constitucional, supralegal ou ordinária que as normas internacionais podem formalmente ocupar ${ }^{29}$ - , as sentenças internacionais devem gozar de status de título executivo ${ }^{30}$, na medida em que houver submissão brasileira à jurisdição internacional de determinado tribunal internacional.

Conforme já se afirmou, o mesmo ato jurídico legítimo para submeter o Brasil à jurisdição internacional também o é para submetê-lo às decisões legitimamente provenientes do respectivo tribunal internacional. O art. 13 do Código de Processo Civil de 2015 consiste, nesse sentido, em verdadeira ponte entre a ordem processual nacional e a internacional, ao estabelecer que as normas processuais internacionais, oriundas de convenções devidamente ratificadas pelo Brasil, terão prevalência sobre as internas. Desse modo, sendo as sentenças internacionais dispensadas de atos de internalização, produzem efeitos automáticos no âmbito doméstico, superando eventuais obstáculos formais.

Tal entendimento está em perfeita harmonia com os princípios constitucionais regentes da atuação brasileira no âmbito internacional (art. $4^{\circ}$, da CRFB/88) - especialmente no que se refere ao inciso VII, que assevera a solução pacífica dos conflitos. Ademais, os Atos das Disposições Constitucionais Transitórias, art. $7^{\circ}$, é enfático no sentido de que “o Brasil propugnará pela formação de um tribunal internacional dos direitos humanos", confirmando a vocação constitucional brasileira para a plena inserção em jurisdições internacionais.

O Brasil, atualmente, reconhece e se submete à jurisdição internacional da Corte Internacional de Justiça ${ }^{31}$, do Tribunal Internacional do Direito do $\mathrm{Mar}^{32}$, do Órgão de Solução de Controvérsias da $\mathrm{OMC}^{33}$, do Tribunal Penal Internacional ${ }^{34}$, da Corte Interamericana de Direitos Humanos ${ }^{35}$ e do Tribunal Permanente de Revisão do Mercosul ${ }^{36}$.

29 BRASIL. Supremo Tribunal Federal. Recurso Extraordinário (RE) n. 466.343-SP. Ministro Cezar Peluso. Tribunal Pleno. Data de Julgamento: 03 de dezembro de 2008. Data de Publicação: 5 de junho de 2009.

30 RESENDE, Augusto César Leite de. A executividade das sentenças da Corte Interamericana de Direitos Humanos no Brasil. Revista de Direito Internacional, Brasília, v. 10, n. 2, 2013.

31 Promulgado pelo Decreto n. 19.841, de 22 de outubro de 1945.

32 Promulgado pelo Decreto n. 99.165, de 12 de março de 1990.

33 Promulgado pelo Decreto n. 1.355, de 30 de dezembro de 1994.

34 Promulgado pelo Decreto n. 4.388, de 25 de setembro de 2002.

35 Promulgado pelo Decreto n. 4.463, de 08 de novembro de 2002.

36 Promulgado pelo Decreto n. 4.982, de 09 de fevereiro de 2004. 
Assim, as decisões provenientes das jurisdições internacionais, as quais o Brasil se submete, não dependem de atos domésticos que as internalizem, como ocorre com as decisões estrangeiras. Dito de outro modo, não há de se falar em necessidade de ato de reconhecimento formal e posterior da ordem nacional em relação à sentença internacional, pois tal ato, capaz de conferir legitimidade ao órgão internacional prolatante, deu-se no momento da submissão a sua jurisdição internacional. Desse modo, a sentença internacional é plenamente apta à produção de efeitos jurídicos no âmbito doméstico.

Cumpre salientar, nessa perspectiva, que o próprio Superior Tribunal de Justiça (STJ) já teve a possibilidade de se manifestar sobre a matéria ${ }^{37}$. Ao analisar o pedido de homologação da Sentença Estrangeira Contestada n. 2.707, de relatoria do Min. Francisco Falcão, a Corte Especial do STJ indeferiu o pedido pois, a bem da verdade, se tratava de sentença internacional proferida pela Corte Permanente de Justiça Internacional. Após concluir que inexistia sentença estrangeria, mas sim uma decisão internacional proferida por um tribunal internacional, especificamente em contencioso envolvendo o Brasil e a França, a Corte Especial destacou que tal ato prescinde de qualquer tipo de exequatur ou homologação ${ }^{38}$.

Ao se falar em cumprimento de sentenças internacionais, justificável a correlação mental com o sistema de execução coercitiva existente no âmbito interno, com o qual se tem habitual proximidade, na mesma medida em que é justificável a relação estabelecida entre tribunais internacionais e tribunais domésticos. Apesar de compreensível, deve-se ter atenção às especificidades de cada um dos planos ${ }^{39}$. O sistema de execução estatal de sentenças domésticas é marcado pela estrutura coercitiva que o sustenta, a que se deve em grande medida sua efetividade. No âmbito da jurisdição internacional, entretanto, inexiste estrutura formal e legal desenhada para dar cumprimento coercitivo às decisões emanadas

37 GUERRA, Gustavo Rabay; MARCOS, Henrique J. Bezerra. O drible continental: a margem de apreciação nacional na decisão de convencionalidade do crime de desacato pelo Superior Tribunal de Justiça. Revista da Faculdade de Direito - UFPR. Curitiba, v. 63, n. 2, maio/ago. 2018. p. 183.

38 BRASIL. Superior Tribunal de Justiça. Sentença Estrangeira Contestada (SEC) n. 2.707. Ministro Francisco Falcão. Corte Especial. Data de Julgamento: 3 de dezembro de 2008. Data de Publicação: 19 de fevereiro de 2009.

39 GUZMAN, Andrew T. International Tribunals: a rational choice analysis. Berkeley Law Scholarship Repository, University of Pennsylvania, Law Review, n. 157, p. 171-235, 2008. p. 178-179. por tribunais internacionais ${ }^{40}$.

Por essa razão, a terceira questão central que Bárbara Campos ${ }^{41}$ apresenta em relação ao cumprimento de sentenças internacionais, ainda que tenha por objeto inicial as sentenças da Corte Interamericana de Direitos Humanos, fez referência à necessidade de arranjos institucionais internos. Isto porque, em que pese não seja necessário ato de internalização da sentença internacional na ordem doméstica - como acontecem com as sentenças estrangeiras, as quais demandam um ato de reconhecimento interno — , sua aplicação imediata é dificultada pela inexistência de mecanismos específicos abstratamente delineados para tal finalidade.

Destarte, diferentemente do que ocorre com as sentenças estrangeiras - provenientes de outra jurisdição nacional e que se pretende que produza efeitos jurídicos na ordem doméstica —, que apresentam sistemas de reconhecimento próprios ${ }^{42}$, o cumprimento de decisões internacionais no Brasil não dispõe de nenhuma norma processual específica. Esse cenário se monstra, ainda, mais complexo quando se cogita na multiplicidade de obrigações - obrigações de dar, de fazer, de não fazer, de entregar - que as sentenças internacionais podem impor aos Estados.

O problema fica mais palpável tendo por base as condenações internacionais já existentes em relação ao Estado brasileiro, como as ocorridas no âmbito da Corte Interamericana de Direitos Humanos. Até o momento, foram oito condenações ${ }^{43}$ : i) Caso Ximenes Lopes, 2006; ii) Caso Escher e outros, 2009; iii) Caso Garibaldi, 2009; iv) Caso Gomes Lund e outros (Guerrilha do Araguaia), 2010; v) Caso Trabalhadores da Fazenda Brasil Verde, 2016; vi) Caso Favela Nova Brasilia, 2017; vii) Caso Povo Indígena Xucuru e seus membros, 2018; viii) Caso Herzog e outros, 2018.

40 VASCONCELOS, Raphael Carvalho. Teoria do Estado e a unidade do direito internacional: domesticando o rinoceronte. Belo Horizonte: Arraes, 2016. p. 138.

41 CAMPOS, Bárbara Pincowsca Cardoso. A trajetória da implementação de sentenças da Corte Interamericana de Direitos Humanos no Brasil. Revista do Instituto Brasileiro de Direitos Humanos, Fortaleza, v. 14, n. 14, 2014.

42 SOUZA, Nevitton V. Sistemas de reconbecimento de sentença estrangeira no Brasil: panorama e adequação normativos. 2015. 137 f. Dissertação (Mestrado) - Programa de Pós-Graduação em Direito da Universidade Federal do Espírito Santo, como requisito parcial à obtenção do grau de Mestre em Direito Processual, Vitória, 2015.

43 Disponível em: < http://www.corteidh.or.cr/cf/jurisprudencia2/index.cfm?>. Acesso em: 9 set. 2018. 
As sentenças internacionais condenatórias acima mencionadas contemplam obrigações de distintas naturezas, no que se destaca como uma das principais peculiaridades das jurisprudências da Corte Interamericana de Direitos Humanos, isto é, a determinação não apenas de medidas de caráter pecuniário, mas também a imputação de medidas de não repetição e de satisfação, no sentido de buscar a reparação integral da violação ${ }^{44}$. Essa multiplicidade de natureza das prestações determinadas enseja maior complexidade ao procedimento de cumprimento.

A reparação integral, que amplia a diversidade de ações que podem ser imputadas pela Corte Interamericana aos Estados partes, fundamenta-se no art. $63.1 \mathrm{da}$ Convenção Americana sobre Direitos Humanos (1969), que permite a determinação não somente de medidas que assegurem aos prejudicados o gozo do seus direitos ou liberdades violados, mas também providências que visem "reparar as consequências da medida ou situação que haja configurado a violação desses direitos, bem como o pagamento de indenização justa à parte lesada".

Destarte, dentre as condenações apontadas, podem ser exemplificadas a seguintes obrigações imputadas ao Estado brasileiro: a) continuar a desenvolver programas de formação e capacitação dos profissionais de saúde ligados à atenção à saúde mental, tendo por base os parâmetros internacionais na matéria ${ }^{45}$; b) investigar e julgar no plano interno, em prazo razoável, os responsáveis pelos atos violadores dos direitos das vítimas ${ }^{46}{ }^{47}$; c) adotar medidas necessárias para tipificar o crime de desaparecimento forçado ${ }^{48}$; ) adotar medidas para afastar

44 CALDERÓN GAMBOA, Jorge F. La reparación integral em la jurisprudencia de la Corte Interamericana de Derechos Humanos: estândares aplicables al nuevo paradigma mexicano. Ciudad de México: Instituto de Investigaciones Jurídicas de la UNAM, 2013. ROUSSET SIRI, Andrés Javier. El concepto de reparación integral en la jurisprudencia de la Corte Interamericana de Derechos Humanos. Revista Internacional de Derechos Humanos, Mendoza, Centro Latinoamericano de Derechos Humanos, ano 1, n. 1, 2011.

45 CORTE INTERAMERICANA DE DIREITOS HUMANOS. Caso Ximenes Lopes Vs. Brasil. Sentença. 4 de julho de 2006. Série C. N. 149.

46 CORTE INTERAMERICANA DE DIREITOS HUMANOS. Caso Escher y otros Vs. Brasil. Exceções Preliminares, Mérito, Reparações e Custas. Sentença. 6 jul. 2009. Série C, N. 200.

47 CORTE INTERAMERICANA DE DIREITOS HUMANOS. Caso Garibaldi Vs. Brasil. Exceções Preliminares, Mérito, Reparações e Custas. Sentença. 23 de setembro de 2009. Série C, N. 203.

48 CORTE INTERAMERICANA DE DIREITOS HUMANOS. Caso Gomes Lund e outros (Guerrilha do Araguaia) Vs. Brasil. Exceções Preliminares, Mérito, Reparações e Custas. Senten- a prescrição do crime de redução à situação análoga à de escravo ${ }^{49}$; e) adotar medidas necessárias para que o Rio de Janeiro estabeleça metas e políticas de redução da violência policial ${ }^{50}$; f) garantir, de forma imediata e efetiva, o direito à propriedade coletiva do Povo Indígena Xucuru sobre seu território ${ }^{51}$; g) adotar medidas para se reconhecer, sem exceção, a imprescritibilidade dos crimes contra a humanidade, segundo os parâmetros internacionais ${ }^{52}$.

Em que pese a Convenção Americana estabeleça que as decisões emanadas pela Corte devem ser cumpridas pelos Estados partes (art. 68.1), bem como são sentenças definitivas e irrecorríveis (art. 67), somente se indicou o percurso processual para a execução da parte indenizatória da sentença condenatória internacional. De acordo com o art. 68.2 da Convenção, a parte pecuniária da sentença poderá ser executada pelo mesmo processo de execução de sentenças contra o Estado. O que, no Brasil, equivale ao processo para execução de sentença em face da Fazenda Pública, perante à Justiça Federal, nos termos dos artigos 109, III, e 100 da Constituição de 1988; e dos artigos 910, 534 e 535 do Código de Processo Civil de 2015.

Ao analisar as determinações da Convenção Americana, Vittorio Corasaniti observa que, entre os artigos 63 e 68, há uma "relação imperfeita", na medida em que estabelece a reparação integral e sua ampla abrangência — para além de medidas indenizatórias —, mas somente apresenta procedimento para a execução das compensações econômicas ${ }^{53}$.

Infere-se da Convenção Americana que foi deixado

ça. 24 de novembro de 2010. Série C, N. 219.

49 CORTE INTERAMERICANA DE DIREITOS HUMANOS. Caso Trabalhadores da Fazenda Brasil Verde Vs. Brasil. Exceções Preliminares, Mérito, Reparações e Custas. Sentença. 20 de outubro de 2016. Série C, N. 318.

50 CORTE INTERAMERICANA DE DIREITOS HUMANOS. Caso Favela Nova Brasília Vs. Brasil. Exceções Preliminares, Mérito, Reparações e Custas. Sentença. 16 de fevereiro de 2017. Série C, N. 333.

51 CORTE INTERAMERICANA DE DIREITOS HUMANOS. Caso Povo Indígena Xucuru e seus membros Vs. Brasil. Exceções Preliminares, Mérito, Reparações e Custas. Sentença. 5 de fevereiro de 2018. Série C, N. 346.

52 CORTE INTERAMERICANA DE DIREITOS HUMANOS. Caso Herzog e outros Vs. Brasil. Exceções Preliminares, Mérito, Reparações e Custas. Sentença. 15 de março de 2018. Série C, N. 353.

53 CORASANITI, Vittorio. Implementación de las sentencias y resoluciones de la Corte Interamericana de Derechos Humanos: un debate necessário. Revista IIDH, San José, v. 49, 2009. 
aos Estados a incumbência de estabelecerem os mecanismos internamente adequados para proporcionar a implementação das decisões internacionais oriundas da Corte Interamericana ${ }^{54}$. Dessa forma, em que pese o caminho indicado para a execução das condenações pecuniárias, no Brasil percorrê-lo resvalaria em ao menos dois empecilhos. O primeiro é atinente aos custos e à morosidade do processo de execução em face da Fazenda Pública, notadamente um obstáculo a mais para o alcance da reparação pretendida. O segundo tem relação com o sistema de precatórios adotado pela Constituição Federal, o qual teria a potencialidade real de neutralizar os objetivos reparatórios do sistema de proteção.

Em vista disso, Barbara Campos ${ }^{55}$ observa que foram adotados arranjos institucionais a fim de dar cumprimento às decisões. Esses arranjos, verificados primeiramente no Caso José Pereira - o primeiro acordo de solução amistosa que envolveu o Brasil e a Comissão Interamericana de Direitos Humanos ${ }^{56}$ - , consistiu no encaminhamento pelo Executivo Federal de projeto de lei ao Congresso Nacional, em regime de urgência, a fim de determinar o pagamento à vítima. Foi preciso a criação da Lei n. 10.706, de 2003, uma vez que não havia dotação orçamentária que autorizasse o Executivo a efetuar o pagamento de forma autônoma.

No esforço de aprimorar os mecanismos de cumprimento da parte pecuniária das sentenças internacionais por condenações em matéria de direitos humanos, a partir de 2004, na Lei Anual Orçamentária passou a ser prevista dotação orçamentária específica para tal finalidade, alocada no âmbito da Secretaria de Direitos Humanos (SDH). Observa-se, portanto, um deslocamento do cumprimento decisório, nesse caso, do Poder Judiciário para o Executivo, com vistas a facilitar a satisfação das sentenças internacionais condenatórias, ao menos em sua parte pecuniária.

Inobstante o arranjo encontrado, nem mesmo a parte pecuniária da sentença internacional restou plenamente afastada de obstáculos, uma vez que dependente

54 TRINDADE, Antonio Augusto Cançado. Compliance with judgments and decisions: the experience of the inter-american court of human rights: a reassessment. Revista do Instituto Brasileiro de Direitos Humanos, Fortaleza, v. 13, n. 13, p. 29-36, 2013.

55 CAMPOS, Bárbara Pincowsca Cardoso. A trajetória da implementação de sentenças da Corte Interamericana de Direitos Humanos no Brasil. Revista do Instituto Brasileiro de Direitos Humanos, Fortaleza, v. 14, n. 14, 2014.

56 Disponível em: <https://cidh.oas.org/annualrep/2003port/ Brasil.11289.htm>. Acesso em: 9 set. 2018. de dotação em quantidade suficiente para adimplir com os comandos decisórios, bem como pelas dificuldades para habilitar sucessores de vítimas já falecidas. É o que se observa na decisão da $1^{a}$ Vara Federal de Itaboraí ${ }^{57}$, no Rio de Janeiro, datada de 02 de setembro de 2015, na qual a Juíza Federal Isabela Ferrari dá procedência à ação movida pela União Federal, em sede de jurisdição voluntária, a fim de dar cumprimento à obrigação internacional oriunda da condenação do Brasil, pela Corte Interamericana de Direitos Humanos, no caso Guerrilha do Araguaia (2010). Como os beneficiados eram herdeiros de Elena Gibertini Castiglia, mãe do desaparecido Líbero Giancarlo Castiglia, foi necessário reconhecimento judicial para que a União pudesse realizar as devidas indenizações aos sucessores da vítima.

Por outro lado, as obrigações extra pecuniárias das sentenças internacionais, notadamente as que se dirijam a atos a serem realizados pelo Legislativo e Judiciário dever de investigar, processar e julgar; conclusão célere de processos judiciais; implementação de política legislativa, mediante criação ou revogação de normas; dentre outras -, continuam com impasses institucionais, na medida em que inexiste caminho normativo pavimentado em abstrato.

\section{Propostas legislativas nacionais}

A ausência de mecanismos erigidos com a finalidade de proporcionar uma implementação mais célere de sentenças internacionais é notada há tempos pela doutrina ${ }^{58}$. Também o Parlamento brasileiro já observou a tramitação de projetos de leis com essa finalidade. Tais esforços legislativos visam alcançar as chamadas "leis-ponte" ou "leis de implementação", que são instrumentos normativos que estabelecem procedimentos em abstrato para a implementação, no âmbito doméstico, das sentenças emanadas de tribunais internacionais.

A primeira tentativa se deve ao Projeto de Lei n.

57 BRASIL. Tribunal Federal Regional da $2^{\mathrm{a}}$ Região. Seção Judiciária do Rio de Janeiro. $1^{\text {a }}$ Vara Federal de Itaboraí. Procedimento de Jurisdição Voluntária n. 0183301-69.2014.4.02.5107. Juíza Federal Isabela Ferrari. Data de Julgamento: 02/09/2015.

58 PIOVESAN, Flávia. Sistema Interamericano de Direito $\mathrm{Hu}-$ manos: impacto transformador, diálogos jurisdicionais e os desafios da reforma. Revista Direitos Emergentes na Sociedade Global, Santa Maria - RS, v. 3, n. 1, p. 76-101, jan./jun. 2014. RAMOS, André de Carvalho. Processo internacional dos direitos humanos. São Paulo: Saraiva, 2012. 
3.214/2000, de autoria do Deputado Marcos Rolim, que acabou arquivado em $2003^{59}$. Segundo observado na ementa do projeto, este tinha como escopo dispor sobre os efeitos jurídicos das decisões da Comissão Interamericana de Direitos Humanos e da Corte Interamericana de Direitos Humanos.

De modo geral, a proposta visava reconhecer a parte indenizatória das decisões internacionais como títulos executivos judiciais, sujeitando-os à execução direta contra a Fazenda Pública. Reconhecia, ainda, a natureza alimentícia de tais créditos, dando-lhe posição privilegiada em relação aos demais créditos. Previa, também, o cabimento de ação regressiva da União contra os sujeitos responsáveis, direta ou indiretamente, pelos atos ilícitos que ensejaram a decisão de caráter indenizatório — independentemente de serem pessoas físicas ou jurídicas, de direito privado ou público.

Também o Projeto de Lei n. 4.667/2004, de autoria do Deputado José Eduardo Cardozo, dispunha sobre o assunto, tendo sido arquivado em $2014^{60}$. Esse projeto, que dispunha sobre os efeitos jurídicos das decisões dos Organismos Internacionais de Proteção aos Direitos Humanos, tinha inicialmente conteúdo similar ao do PL 3.314/2000.

Durante a tramitação pelas comissões internas na Câmara dos Deputados, ganhou corpo e foi aprovada a versão substitutiva com redação final do Deputado Luiz Couto, cuja proposta passou a figurar ser de responsabilidade do ente federado responsável pela violação o cumprimento da obrigação de reparar as vítimas. Em todo caso, a fim de evitar o descumprimento da sentença, a União poderia proceder a reparação, permanecendo a obrigação originária do ente violador. Deixou, todavia, de prever a natureza de titulo executivo judicial da sentença internacional.

Após ser enviado ao Senado Federal, e nele obter parecer favorável do relator na Comissão de Constituição, Justiça e Cidadania, o PL 4.667/2004 foi arquivado por ter chegado o fim da $54^{a}$ Legislatura, nos termos do art. 332 do Regimento Interno.

Em 2016, foi apresentado pelo Senador Randolfe

59 Disponível em: <http://www.camara.gov.br/proposicoesWeb/fichadetramitacao?idProposicao $=19288>$. Acesso em: 9 set. 2018.

60 Disponível em: <https://www25.senado.leg.br/web/atividade/materias/-/materia/98360>. Acesso em: 9 set. 2018.
Rodrigues o Projeto de Lei do Senador n. 220/2016 ${ }^{61}$, com a finalidade de dispor sobre o cumprimento de decisões da Comissão Interamericana de Direitos Humanos e das sentenças da Corte Interamericana de Direitos Humanos.

Dentre as propostas até aqui apresentadas, o PLS n. 220/2016 se mostra o mais robusto, bem como apresenta maiores impactos sobre a implementação das decisões internacionais em matéria de direitos humanos. Na versão substitutiva aprovada pela Comissão de Relações Exteriores e Defesa Nacional (CRE), na forma da Emenda n. 1 - CRE (Substitutiva), o art. $1^{\circ}$ amplia o escopo normativo, alcançando todas as decisões e sentenças proferidas por tribunais internacionais e organismos internacionais de proteção aos direitos humanos, que versem sobre responsabilização internacional baseada em tratado internacional ao qual a República Federativa do Brasil esteja vinculada.

Ademais, explicita a obrigatoriedade e a produção automática de efeitos, assim como o dever de ser observada por todos os Poderes da União, dos Estados, do Distrito Federal e dos Municípios, bem com pelo Ministério Público. Reforça a desnecessidade de procedimento homologatório. Afasta obstáculos como a prescrição, decadência, coisa julgada, anistia ou outros semelhantes, devendo ser as sentenças internacionais em matéria de direitos humanos cumpridas com prioridade. Prevê, ainda, a dotação orçamentária destinada, especificamente, ao cumprimento das sentenças internacionais.

Quanto à parte indenizatória das sentenças internacionais, reconhecem sua natureza de título executivo judicial, submetendo-se aos procedimentos de execução direta contra a Fazenda Pública Federal ou execução direta administrativa - para os quais estabelece peculiaridades procedimentais, como o prazo de 90 (noventa) dias para o pagamento na execução por quantia certa. Os créditos delas oriundas terão natureza alimentícia. O direito de regresso da União está assegurado pelas disposições do projeto, desde que no prazo de 60 (sessenta) dias após o pagamento da indenização aos beneficiados.

A bem da verdade, ao modificar as disposições do Código de Processo Civil relativas aos títulos executivos judiciais, inserindo nesse rol as decisões e sentenças

61 Disponível em: <https://www25.senado.leg.br/web/atividade/materias/-/materia/125951>. Acesso em: 9 set. 2018. 
internacionais de direitos humanos, o legislador visa estabelecer a exigibilidade de obrigações de pagar quantia, de fazer, de não fazer ou de entrega de coisa. Destarte, não somente as obrigações de caráter pecuniário poderão ser executadas judicialmente, mas também obrigações de outras naturezas que são frequentemente utilizadas pela Corte Interamericana de Direitos Humanos como medidas de reparação integral.

Destaca-se, ainda, a previsão do art. $8^{\circ}$, no tocante às decisões e sentenças internacionais de caráter não indenizatórias, dispondo que caberá ao Ente Federado cujas competências estiverem diretamente relacionadas com o cumprimento da decisão adotar as medidas que se fizerem necessárias, sejam elas de natureza administrativa, legislativa ou jurisdicionais.

Após obter a aprovação da Comissão de Relações Exteriores e Defesa Nacional (CRE), em 25 de maio de 2017, o projeto seguiu para análise da Comissão de Assuntos Econômicos (CAE), na qual obteve finalmente, em 16 de outubro de 2018, parecer. A CAE aprovou, contudo, o parecer do relator, o Senador Pedro Chaves, contrário à aprovação do PLS n. 220/2016. Segundo o parecer emitido pela CAE, a negativa do projeto deveu-se a dois motivos principais: (i) ausência de estimativa do impacto financeiro da proposta e (ii) inoportunidade no projeto face ao momento em que "o país atravessa severa crise fiscal" ${ }^{\prime 62}$.

Em relação à primeira justificativa para a rejeição, oportuno destacar que a ausência de estimativa do impacto financeiro da proposta legislativa pode ser suprida mediante simples solicitação direcionada ao Executivo, com base no disposto no $\$ 1^{\circ}$ do art. 112 da Lei n. 13.473/2017. No tocante à segunda justificativa, em que pese lastreada em famigerada especulação em relação à crise fiscal, oportuno pontuar que no dia 7 de novembro de 2018, portanto posterior à rejeição do PSL 220/2016 pela CAE, o Senado Federal aprovou o aumento de $16,3 \%$ aos salários dos ministros do Supremo Tribunal Federal, provocando, após a sanção presidencial em 26 de novembro de $2018^{63}$, um aumento de $\mathrm{R} \$$ 1,7 bilhão (um vírgula sete bilhão de reais) a ser arcado pela União em 2019 - conforme nota técnica da Con-

62 Disponível em: <https://www25.senado.leg.br/web/atividade/materias/-/materia/125951>. Acesso em: 26 nov. 2018.

63 Materializada na Lei n. 13.752, de 26 de novembro de 2018. Disponível em: <http://www.planalto.gov.br/ccivil_03/_ato20152018/2018/Lei/L13752.htm>. Acesso em: 26 nov. 2018. sultoria de Orçamento do Senado ${ }^{64}$. Por consequência, resta evidenciada que, a bem da verdade, trata-se de ausência de prioridade orçamentária.

Atualmente, o PLS n. 220/2016 foi encaminhado à Comissão de Constituição, Justiça e Cidadania (CCJ) do Senado Federal, da qual aguarda parecer e decisão terminativa.

\section{Considerações finais}

Todas as tentativas legislativas até agora empreendidas no Congresso Nacional foram bem restritivas, somente versando sobre as sentenças internacionais em matéria de direitos humanos, olvidando de forma completa a submissão do Brasil a outras jurisdições internacionais, especializadas e de caráter geral. Ademais, as propostas inicialmente giravam em tono do cumprimento da parte pecuniária das ditas sentenças, estabelecendo procedimentos de execução, bem como de direito de regresso.

Apesar de o PLS n. 220/2016 versar, pontualmente, sobre as obrigações não pecuniárias decorrentes dos comandos decisórios internacionais, ao inserir textualmente as decisões internacionais em matéria de direitos humanos no rol dos títulos executivos judiciais, ainda perde a oportunidade de estruturar ações institucionais coordenadas entre os Poderes Constituídos e entre os Entes Federados, com vistas a satisfazer as obrigações internacionais.

Numa perspectiva latino-americana, verifica-se que países como a Colômbia ${ }^{65}$, Costa Rica ${ }^{66}$ e Peru ${ }^{67}$ já possuem normas ou leis especificas (leis-ponte) que versam sobre a implementação doméstica de decisões internacionais. Entretanto, também os referidos países concentram o objeto de suas normas domésticas, de forma restritiva, em relação às decisões em matéria de direitos humanos.

64 Disponível em: <https://www25.senado.leg.br/web/atividade/materias/-/materia/126084>. Acesso em: 26 nov. 2018.

65 BRASIL. Lei $n^{\circ} 288$, de 5 de julbo de 1996. Disponível em: <http://www.suin-juriscol.gov.co/viewDocument. asp?ruta=Leyes $/ 1657653>$. Acesso em: 9 set. 2018.

66 CONVÊNIO Sede entre o Governo de la República de Costa Rica e a Corte Interamericana de Direitos Humanos, concluído em 10 de setembro de 1981. Disponível em: < http://www.corteidh. or.cr/docs/otros/convenio.pdf>. Acesso em: 9 set. 2018.

67 BRASIL. Lei n. 23.506, de 7 de dezembro de 1982. Disponível em: <http://www.refworld.org/cgi-bin/texis/vtx/rwmain/opendocpdf.pdf? reldoc $=\mathrm{y} \&$ docid $=52 \mathrm{cbc} 4 \mathrm{~d} 44>$. Acesso em: 9 set. 2018 . 
Há de se cogitar, no entanto, em ampliar o escopo de aplicação de projetos de leis-ponte, de modo a contemplar todas as sentenças internacionais dos tribunais aos quais o Estado tenha se submetido à jurisdição internacional. Não há motivos razoáveis que justifiquem a restrição empreendida.

É preciso considerar que a inexistência de instrumentos internos que auxiliem a implementação de sentenças internacionais, ao dificultar a satisfação das obrigações internacionais dela decorrentes, podem inserir o Estado em situação de nova responsabilização internacional - uma vez que o descumprimento de sentença internacional constitui nova violação.

Cabe reiterar, nesse sentir, que o Estado não pode alegar razões de direito interno para justificar o inadimplemento de obrigações internacionais - conforme disposto na Convenção de Viena sobre o Direito dos Tratados (1969). Destarte, as dificuldades institucionais advindas da ausência de coordenação entre os Poderes Constituídos ou entre os Entes Federados, bem como a inexistência de esforços envidados no sentido de mitigá-las ou superá-las, não se mostram juridicamente capazes de impedir a situação de nova responsabilização do Estado por descumprimento da sentença internacional.

Abrir o ordenamento jurídico nacional à completa interação com as jurisdições internacionais não trará repercussões negativas aos cidadãos e jurisdicionados brasileiros. Ao contrário, a proteção jurisdicional estendida sobre eles será maior, uma vez que gozarão da segurança do amparo de sistemas construídos para atender demandas impostas pela complexidade das relações jurídicas da sociedade moderna. $\mathrm{O}$ aperfeiçoamento desse plexo de jurisdições existentes, por meio de mecanismos de implementação eficientes, mostra-se essencial à adequada prestação jurisdicional e ao consequente direito ao substancial acesso à justiça no atual cenário de jurisdicionalização da sociedade internacional globalizada.

\section{REFERÊNCIAS}

AZAR, Aïda. L'exécution des décisions de la Cour internationale de justice. Bruxelas: Bruylant: l'Université de Bruxelles, 2003.

BRASIL. Lei n. 23.506, de 7 de dezembro de 1982. Disponível em: <http://www.refworld. org/cgi-bin/texis/vtx/rwmain/opendocpdf. pdf? reldoc $=y \&$ docid $=52 \mathrm{cbc} 4 \mathrm{~d} 44>$. Acesso em: 9 set. 2018.

BRASIL. Lei $n^{\circ}$ 288, de 5 de julho de 1996. Disponível em: <http://www.suin-juriscol.gov.co/viewDocument. asp?ruta=Leyes/1657653 >. Acesso em: 9 set. 2018.

BRASIL. Superior Tribunal de Justiça. Sentença Estrangeira Contestada (SEC) n. 2.707. Ministro Francisco Falcão. Corte Especial. Data de Julgamento: 3 de dezembro de 2008. Data de Publicação: 19 de fevereiro de 2009.

BRASIL. Supremo Tribunal Federal. Recurso Extraordinário (RE) n. 466.343-SP. Ministro Cezar Peluso. Tribunal Pleno. Data de Julgamento: 03 de dezembro de 2008. Data de Publicação: 5 de junho de 2009.

CALDERÓN GAMBOA, Jorge F. La reparación integral em la jurisprudencia de la Corte Interamericana de Derechos Humanos: estândares aplicables al nuevo paradigma mexicano. Ciudad de México: Instituto de Investigaciones Jurídicas de la UNAM, 2013.

CAMPOS, Bárbara Pincowsca Cardoso. A trajetória da implementação de sentenças da Corte Interamericana de Direitos Humanos no Brasil. Revista do Instituto Brasileiro de Direitos Humanos, Fortaleza, v. 14, n. 14, 2014.

CAPPELLETTTI, Mauro; GARTH, Bryant. Acesso à justiça. Porto Alegre: Fabris, 1988.

CAPUCIO, Camilla. A natureza jurídica das decisões do Sistema de Solução de Controvérsias da OMC: solucionando um imbróglio. Revista de Direito Internacional, Brasília, v. 14, n. 1, p. 316-340, 2017.

CAPUCIO, Camilla. Implementação das decisões do Sistema de Solução de Controvérsias da OMC e mecanismos de efetivação no direito brasileiro. 2014. 391 f. Tese (Doutorado) - Programa de Pós-Graduação em Direito Internacional da Universidade de São Paulo, São Paulo, 2014.

CHARNEY, Jonathan I. Is international law threatened by multiple international tribunals?. Recueil des Cours, Academie de Droit International de la Haye, v. 271, p. 101-382, 1998.

CONVÊNIO Sede entre o Governo de la República de Costa Rica e a Corte Interamericana de Direitos Humanos, concluído em 10 de setembro de 1981. Disponível em: <http://www.corteidh.or.cr/docs/otros/convenio.pdf $>$. Acesso em: 9 set. 2018.

CORASANITI, Vittorio. Implementación de las sen- 
tencias y resoluciones de la Corte Interamericana de Derechos Humanos: un debate necessário. Revista IIDH, San José, v. 49, 2009.

GEROMEL, Vitor. Tribunais internacionais e o Poder Judiciário brasileiro. 2014. 172 f. Dissertação (Mestrado) Programa de Pós-Graduação em Direito Internacional da Universidade de São Paulo, São Paulo, 2014.

GUERRA, Gustavo Rabay; MARCOS, Henrique J. Bezerra. O drible continental: a margem de apreciação nacional na decisão de convencionalidade do crime de desacato pelo Superior Tribunal de Justiça. Revista da Faculdade de Direito - UFPR. Curitiba, v. 63, n. 2, maio/ ago. 2018.

GUZMAN, Andrew T. International Tribunals: a rational choice analysis. Berkeley Law Scholarship Repository, University of Pennsylvania, Law Review, n. 157, p. 171235, 2008.

KARAGIANNIS, Syméon. La multiplication des juridictions internationales: un système anarchique?. LA JURIDICTIONNALIS ATION du droit international. Societe Française pour le Droit International, Paris: Pedone, 2003.

MENEZES, Wagner. Ordem global e transnormatividade. Ijuí: Unijuí, 2005.

MENEZES, Wagner. Tribunais Internacionais: jurisdição e competência. São Paulo: Saraiva, 2013.

PIOVESAN, Flávia. Sistema Interamericano de Direito Humanos: impacto transformador, diálogos jurisdicionais e os desafios da reforma. Revista Direitos Emergentes na Sociedade Global, Santa Maria - RS, v. 3, n. 1, p. 76-101, jan./jun. 2014.

POLIDO, Fabrício B. P. Direito processual internacional e o contencioso internacional privado. Curitiba: Juruá, 2013.

RAMOS, André de Carvalho. Processo internacional dos direitos humanos. São Paulo: Saraiva, 2012.

RESENDE, Augusto César Leite de. A executividade das sentenças da Corte Interamericana de Direitos $\mathrm{Hu}$ manos no Brasil. Revista de Direito Internacional, Brasília, v. 10, n. 2, 2013.
REZEK, José Francisco. Direito internacional público: curso elementar. 15. ed. São Paulo: Saraiva, 2014.

ROUSSET SIRI, Andrés Javier. El concepto de reparación integral en la jurisprudencia de la Corte Interamericana de Derechos Humanos. Revista Internacional de Derechos Humanos, Mendoza, Centro Latinoamericano de Derechos Humanos, ano 1, n. 1, 2011.

SHAW, Malcolm. International law. 6. ed. New York: Cambridge University Press, 2008.

SOUZA, Nevitton V. Sistemas de reconhecimento de sentença estrangeira no Brasil: panorama e adequação normativos. 2015, 137 f. Dissertação (Mestrado) - Programa de Pós-Graduação em Direito da Universidade Federal do Espírito Santo, Vitória, 2015.

SPAIN, Anna. Using international dispute resolution to address the compliance question in international law. Georgetown Journal of International Law, Washington, D.C., v. 40, n. 3, 2009.

TOMUSCHAT, Christian. International law: ensuring the survival of mankind on the eve of a new century: general course on public international law. Recueil des Cours, Academie de Droit International de la Haye, v. 281, p. 9-438, 1999.

TRINDADE, Antonio Augusto Cançado. Compliance with judgments and decisions: the experience of the inter-american court of human rights: a reassessment. Revista do Instituto Brasileiro de Direitos Humanos, Fortaleza, v. 13, n. 13, p. 29-36, 2013.

TRINDADE, Antonio Augusto Cançado. El derecho de acceso a la justicia em su amplia dimension. Santiago: Librotecnia, 2008.

VASCONCELOS, Raphael Carvalho. Teoria do Estado e a unidade do direito internacional: domesticando o rinoceronte. Belo Horizonte: Arraes, 2016.

WENDPAP, Friedmann; KOLOTELO, Rosane. Direito internacional. Rio de Janeiro: Elsevier, 2007. 
Para publicar na Revista de Direito Internacional, acesse o endereço eletrônico www.rdi.uniceub.br ou www.brazilianjournal.org.

Observe as normas de publicação, para facilitar e agilizar o trabalho de edição. 